\title{
Kernos
}

Revue internationale et pluridisciplinaire de religion grecque antique

$16 \mid 2003$

Varia

\section{BOUVIER, Le sceptre et la lyre}

\section{Olivier Gengler}

\section{(2) OpenEdition}

\section{Journals}

Édition électronique

URL : http://journals.openedition.org/kernos/840

DOI : $10.4000 /$ kernos.840

ISSN : 2034-7871

Éditeur

Centre international d'étude de la religion grecque antique

Édition imprimée

Date de publication : 1 janvier 2003

Pagination : 364-365

ISSN : 0776-3824

\section{Référence électronique}

Olivier Gengler, «D. BOuvier, Le sceptre et la lyre », Kernos [En ligne], 16 | 2003, mis en ligne le 14 avril 2011, consulté le 24 septembre 2020. URL : http://journals.openedition.org/kernos/840 ; DOI : https:// doi.org/10.4000/kernos.840 


\section{Comptes rendus et notices bibliographiques}

David Bouvier, Le sceptre et la lyre. L'Iliade ou les béros de la mémoire, Grenoble, Jérôme Millon, 2002. 1 vol. $24 \times 16$ cm, 511 p. (Coll. Horos). ISBN : 2-84137122-0.

Pourquoi les héros de l'Iliade se battent-ils? Pour la gloire? Pas précisément, mais plutôt pour s'élever au niveau des hauts faits des hommes de jadis, assurer la vaillance de leur descendance, et laisser pour « les hommes de demain » (essomenoi) la trace de leurs propres hauts faits. Conjuguant les apports de l'analyse littéraire, de la linguistique et de l'anthropologie, l'A. s'est donné ici pour objectif d'éclairer les conditions culturelles de production de l'fliade. C'est la mémoire qui sert de fil conducteur à cette étude : mémoire des hauts faits héroïques, fondement de la justice et de la cohésion sociale, mais aussi mémoire du poète habilité à chanter les héros. Ceux-ci, en effet, ne seraient rien sans les poètes qui les chantent.

En effet, sans destinataire explicite (Introduction : «Le destinataire oublié », p. 13-50), le poème semble trouver sa motivation dans l'attente du héros - incarné de manière emblématique par Hector - de laisser le souvenir de ses actions exemplaires aux générations futures (Chap. 1: «Hector et les hommes de demain», p. 51-133). Le futur, c'est Astyanax, destiné à mesurer sa valeur à l'aune de celle de son père; c'est aussi l'auditeur ou le lecteur du poème invité à se souvenir. À partir de ce premier acquis, l'A. développe ensuite son propos sur deux plans imbriqués: l'ordre des générations dans la morale héroïque et la perpétuation de la tradition poétique. Ainsi, selon l'A., l'Iliade refléterait à la fois sa propre utilité sociale, dans la mesure où elle invite la communauté à conserver mémoire de son passé, et la conscience qu'a le poète d'être lui-même tributaire de la mémoire.

L'A. s'attache donc à explorer les relations de la langue homérique avec la mémoire (Chap. 2: "L'invention d'une langue de la mémoire", p. 135-231). Plutôt que l'héritière figée d'une tradition séculaire, la langue de l'épopée est considérée ici comme un instrument de création, fruit d'une longue évolution, porteuse d'un bagage traditionnel, mais dont la souplesse, encadrée par l'hexamètre, permet une perpétuelle recomposition qui garantit la continuité de la tradition. L'lliade ne serait donc pas le reflet plus ou moins ténu de poèmes répétés depuis toujour's, mais bien l'ultime incarnation d'une tradition orale saisie par l'écriture. Précisément, derrière le renversement de perspective, qui rend le poète nécessaire aux héros, l'A. voit les doutes d'une tradition poétique orale remise en question par l'apparition de l'écriture. Le souci du héros de laisser un souvenir durable deviendrait ainsi l'exact correspondant de la crainte de l'aède de voir s'interrompre la tradition dont il est l'héritier (voir la seconde partie de la Conclusion, p. 436-452).

Une fois précisé le rôle de la langue épique, l'A. s'attache à explorer plus profondément l'éthique hérö́que de l'Iliade, et passe d'Hector à Achille. Dans sa colère contre Agamemnon, Achille reste sourd aux sollicitations de l'ambassade du chant IX qui s'efforce de rétablir le droit qui a été rompu dans la dispute (Chap. 3: "L'ordre du sceptre : le héros et la loi », p. 233-311). Dès lors, l'exemple des ancêtres - l'histoire de Méléagre rapportée par Phoinix - doit ramener Achille dans l'ordre social des générations que la poésie tendrait à préserver (Chap. 4: « L'ordre de la lyre : le héros et l'histoire des ancêtres », p. 313-355). Seul Patrocle pourrait peut-être convaincre Achille de reprendre le combat, comme Cléopatra, au nom étrangement proche de celui de Patrocle, avait convaincu Méléagre. Dès lors, à travers l'analyse du nom et de la personnalité, plutôt évanescente, de Patrocle, l'A. s'efforce de montrer comment celui-ci était destiné à rappeler une dernière fois Achille à son devoir (Chap. 5: "Patrocle ou la mémoire de l'Iliade ", p. 357-414). À la suite des Néo-analystes, l'A. voit en Patrocle un double d'Antiloque tel qu'il apparaît dans la geste de Memnon, à savoir un héros qui meurt pour sauver son père. Mais ce héros au nom parfait ne pourra détourner Achille de son refus de combattre que par sa mort, après qu'Achille aura opposé à ses suppliques le désir de voir mourir tant les Grecs que les Troyens. 
Dans la mesure où, par son refus, Achille a menacé la survie de la communauté, la vraie conclusion de l'Iliade est moins à attendre de la réconciliation avec Agamemnon, qui intervient dès le chant XIX, que de la confrontation du héros avec un père, non pas le sien, mais celui d'Hector, venu réclamer la dépouille de son fils, au chant XXIV. Ramené à la raison des ancêtres par Priam, Achille réintègre sa place dans l'ordre des générations (Conclusion, p. 415-436). Le poème apparaît donc comme un garant de la cohésion sociale par l'inscription de l'individu dans la tradition de ses pères.

L'ouvrage a été soutenu comme thèse de doctorat en 1998 à l'Université de Genève. L'exposé très systématique, accompagné d'une importante bibliographie et d'index, est parfois ralenti par des répétitions ou par des citations redondantes, et ce que l'analyse gagne en rigueur, elle le perd quelque peu en lisibilité. Mais on appréciera de voir se développer, au fil d'une lecture érudite des poèmes, la vision d'un interprète minutieux, qui n'a pas reculé devant l'audace de se mesurer à une ouvre comme l'Iliade. Même si les arguments semblent quelques fois ténus, la thèse avancée ici est séduisante et jette indubitablement un éclairage neuf sur une œuvre si connue et pourtant toujours à découvrir.

O. Gengler (EHESS-Paris)

Paolo Scarpi (éd.), Le Religioni dei misteri. Vol. I: Eleusi, Dionisismo, Orfismo. Vol. II: Samotracia, Andania, Iside, Cibele e Attis, Mitraismo, Milano, Arnaldo Mondadori Editore, Fondazione Lorenzo Valla, 2002. 2 vol. $13 \times 20 \mathrm{~cm}$, XLVII $+616 \mathrm{p}$. \& LXXXII + 692 p. (Scrittori greci e latini). ISBN : 88-04-50667-9 \& 88-04-50317-3.

Voici un volumineux et important ouvrage dont il convient d'annoncer sans délais la parution, quitte à se borner ici à une présentation essentiellement descriptive. Il s'agit, en effet, d'un recueil des témoignages écrits, littéraires et épigraphiques (à l'exclusion donc des documents archéologiques et iconographiques) relatifs aux principaux cultes à mystères de l'Antiquité gréco-romaine, et ce recueil se signale par une double originalité. D'une part, à considérer en particulier chacun des huit cultes visés, c'est la première fois que sont en même temps rassemblés méthodiquement, traduits et commentés les textes anciens qui nous les font connaître. D'autre part, la réunion de ces textes dans un même ouvrage permet une vue d'ensemble des mystères antiques et incite d'autant plus à une démarche comparative que les témoignages sont, pour chaque culte, regroupés sous les mêmes rubriques, si ce n'est que les plus richement documentés peuvent requérir une ou deux rubriques supplémentaires (e.g., "Petits et grands mystères » pour Éleusis), tandis que d'autres affichent quelquefois une lacune. Le tronc commun est le suivant: « Mythes de fondation ", «Sacerdoce », "Culte et pratiques rituelles », «Initiation », "Secret et interdictions ", "Eschatologie » ou "Sotériologie »; la numérotation des témoignages est faite par rubrique, chacune de celles-ci étant précédée d'une lettre. Eu égard à ce qui caractérise les cultes à mystères, cette division semble pertinente et permet à tout le moins une mise en ordre fort bienvenue des témoignages; le cas particulier des textes relevant de deux ou de plusieurs rubriques, - songeons par exemple à l'Hymne bomérique à Déméter, cité ici in extenso -, est résolu par des reproductions partielles ou par des renvois.

Dans une substantielle introduction de quarante pages, l'A. s'attache tout d'abord à éclairer la notion de mystères, en référence notamment à la terminologie dont usent

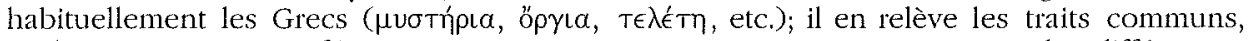
souligne certaines interférences et connexions, mais insiste tout autant sur les différences, récusant à cet égard la tendance à une homogénéisation qu'on observe déjà dans l'Antiquité tardive. Est aussi abordée, avec beaucoup de réserve, la question difficile des origines. L'A. indique encore deux limites données à son travail et s'en explique. Il est évident tout d'abord que le nombre de "mystères " qu'évoquent les sources anciennes en usant du vocabulaire susdit est bien supérieur à huit; il suffit, pour s'en convaincre, de suivre Pausanias dans ses pérégrinations à travers le Péloponèse, par exemple. Les cultes omis dans le présent ouvrage, explique l'A., l'ont été soit en raison de la pauvreté de l'information qui les concerne, soit parce qu'il apparaît, à l'examen, que les connotations mystériques que leur prêtent certains Anciens trop prompts aux assimilations ne se justifient pas; tel est le cas, par exemple, des cultes d'Adonis. Dresser ici ne serait-ce qu'un 